\title{
REBREATHING AND CO-AXIAL CIRCUITS: A COMPARISON OF THE BAIN AND MERA F
}

\author{
R.J. Byrick, E. Janssen and Masao Yamashita
}

\begin{abstract}
This study compares the rebreathing characteristics of the Bain modification of the Mapleson ' $D$ ' type of T-piece circuit with those of the MERA F system which is used with the standard "circle" anaesthetic machine. Six healthy adults anaesthetized with halothane were studied breathing spontaneously. The volume of inspired carbon dioxide was measured on each breath as a measure of rebreathing. The tidal volume (VT) frequency of respiration (f) and blood $\mathrm{PCO}_{2}$ were also noted. These measurements were made initially with either the BAIN or the MERA $F$ system and then changed to the alternate circuit for further studies. All measurements were made with a fresh gas flow rate (FGF) of $100 \mathrm{ml} \cdot \mathrm{kg}^{-1} \cdot \mathrm{min}^{-1}$ which is recommended with the Bain system.

The inspired volume of carbon dioxide (rebreathing) with the Bain system was significantly greater than when the MERA F was used. Although the mean blood $\mathrm{PCO}_{2}$ was not significantly lower when the MERA F was used, some patients who cannot adequately compensate for this inspired carbon dioxide volume did become hypercapneic (maximum $8 \mathrm{kPa}$ [60 torr]). This hypercapnia could be reduced by using a MERA F system.

The MERA $F$ is a co-axial system that combines the convenience of the tube-in-a-tube structure with the beneficial effects of controlled rebreathing during controlled ventilation. In these advantages it is no different from the Bain system. The MERA $F$ however, has the advantage of being adaptable to the commonly used "circle" anaesthetic machines for spontaneous respiration in adults. This eliminates the rebreathing of carbon dioxide at a fresh gas flow of $100 \mathrm{ml} \cdot \mathrm{kg}^{-1} \cdot \mathrm{min}^{-1}$, which occurs in adults during spontaneous respiration. The only disadvantage of the MERA F system that we used in adults was its length $(90 \mathrm{~cm})$. However, from a functional viewpoint, it can be lengthened without altering the rebreathing characteristics of the system.
\end{abstract}

Key Words: Anaesthetic Equipment, Mera F, Bain.

\section{INTRODUCTION}

THERE HAS BEEN considerable controversy in the recent anaesthetic literature ${ }^{1-4}$ concerning the safety of using the Bain modification of the Mapleson ' $D$ ' circuit with low fresh gas flow (FGF) rates during spontaneous respiration. The recommended FGF in the package insert is $100 \mathrm{ml} \cdot \mathrm{kg}^{-1} \cdot \mathrm{min}^{-1}$ for spontaneously breathing adults. We have demonstrated ${ }^{4}$ that all adults under halothane anaesthesia rebreathe significant volumes of carbon dioxide when the Bain breathing system is used at the recommended FGF. This verifies the theoretical predictions of

R.J. Byrick, M.D., F.R.C.P.(C), Assistant Professor, Dept. of Anaesthesia, St. Michael's Hospital, Toronto, Ontario; E. Janssen, R.R.T.. St. Michael's Hospital, Toronto, Ontario; Masao Yamashita, M.D., Assistant Lecturer, Dept. of Anesthesiology, Hirosaki University, Hirosaki, Aomori-Ken Japan.

Correspondence to: Dr. R.J. Byrick, Dept. of Anaesthesia, St. Michael's Hospital, 30 Bond Street, Toronto, Ontario, M5B 1W8.

Canad. Anaesth. Soc. J., vol. 28, no. 4, July 1981
Mapleson $^{5}$ and Conway that a FGF of approximately twice the minute ventilation ( $\left(\dot{V}_{E}\right)$ is necessary to prevent rebreathing in a Mapleson ' $D$ ' circuit.

The study ${ }^{6}$ on which the FGF recommendation of $100 \mathrm{ml} \cdot \mathrm{kg}^{-1} \cdot \mathrm{min}^{-1}$ is based showed that many healthy young adults could maintain an arterial carbon dioxide tension of $5.3 \mathrm{kPa}$ (40 torr) by increasing $\dot{V E}$ in response to the inspired carbon dioxide challenge resulting from this low FGF. Anaesthesia reduces the patient's responsiveness and several cases, $4,7,8$ of hypercapnia using the Bain system have been reported. Our previous data ${ }^{4}$ showed that the volume of carbon dioxide rebreathed and the patient's response to this carbon dioxide challenge are unpredictable under clinical conditions. Some patients, with poor responsiveness to carbon dioxide became progressively hypercapneic as FGF was reduced and rebreathing of carbon dioxide increased. Other patients, with intact responsiveness to carbon dioxide, could increase $\dot{V}_{E}$ appropriately and maintain $\mathrm{PCO}_{2}$ constant in spite of carbon 


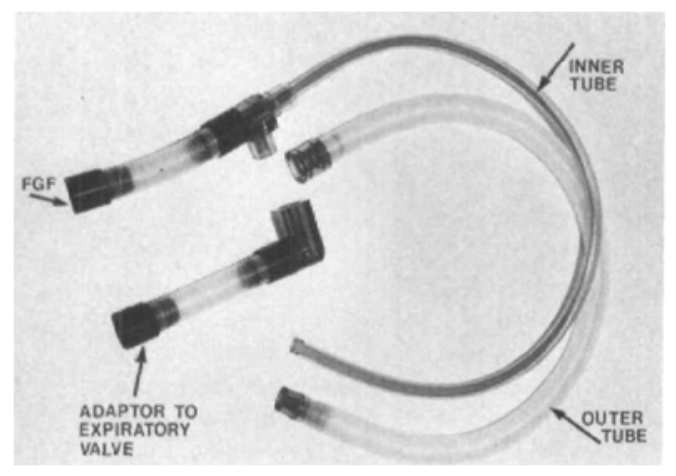

FIGURE I The MERA F circuit is readily assembled from individual pieces after cleaning. The inspiratory fresh gas is delivered through the inner tube to the patient. Exhaled gases are carried away by the outer tube of this co-axial system in a manner identical with the BAIN circuit. The MERA F can be used with the circle system adapter for spontaneous respiration in adults.
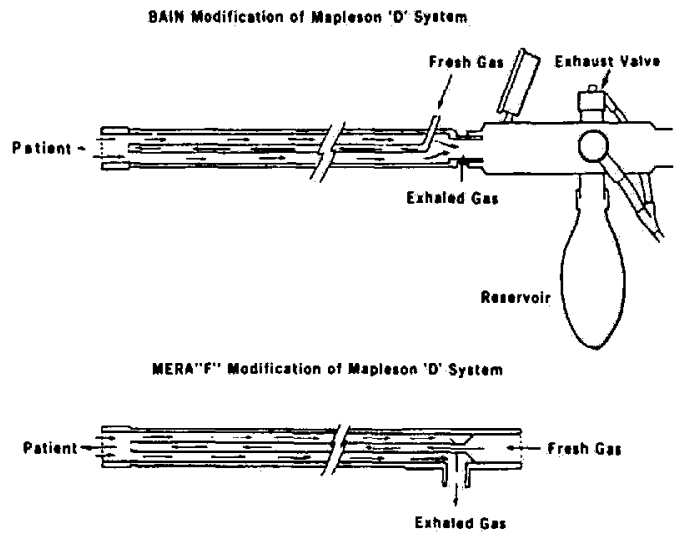

FIgure 2 The BAIN system is shown as used in this study. The MERA F diagram illustrates how this system can be used in the same manner as the BAIN when the adapter (Figures $1 \& 3$ ) is omitted.

dioxide rebreathing. Because of this limitation, many anaesthetists advocate the use of higher FGF rates if this system must be used.

Having recognized the disadvantage of rebreathing ${ }^{9}$ with the Bain system for spontaneous respiration, Fukunaga ${ }^{10}$ has introduced the MERA F circuit* in Japan as a multi-purpose anaesthetic breathing system (Figures 1 \& 3 ). The major innovation with the MERA F is that an adaptor is supplied with the circuit to permit its use with the standard inspiratory and expiratory valves which form the circle system on most anaesthetic machines. This allows the anaesthe-

* The MERA F circuit is manufactured and supplied in Japan by the Senko Medical Instrument Mfs. Co. Ltd. Merasenko, Tokyo, Japan.

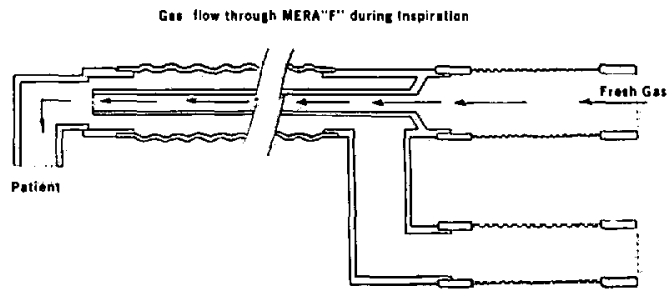

Figure 3a This line diagram depicts the direction of gas flow on inspiration in the MERA F system when used with the inspiratory and expiratory valves of the "circle" machine. These valves prevent the rebreathing of expired gas from the outer tube of the MERA F.

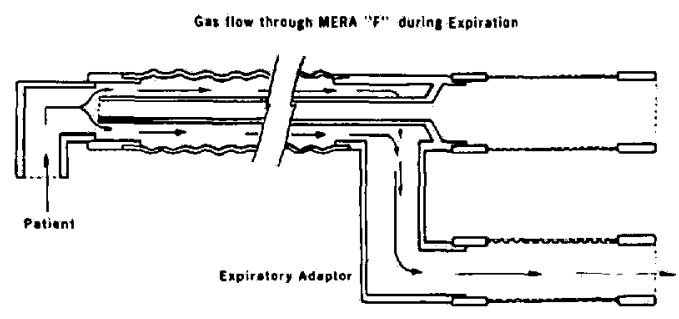

Figure 3b This diagram shows the expired gas passing down the outer tubing of the MERA F system. This expired flow is prevented from moving down the inner tube by the inspiratory valve of the "circle" machine which closes on expiration.

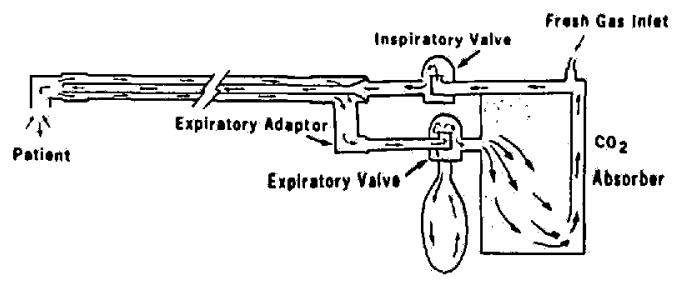

FIgure 3c The MERA F system is shown as used in this study. The adaptor leads the expired gas from the outer tube to the expiratory valve of the "circle" machine.

tist to use the same breathing system (MERA F) as either a modified (co-axial) "circle" system (Figure 3) or as a modified Mapleson 'D' type of T-piece circuit identical to the BAIN system (Figure 2).

The use of the MERA F as a co-axial "circle" system allows one to use low FGF rates with reduced operating room pollution and theoretically to eliminate the risk of carbon dioxide rebreathing during spontaneous respiration. Since the same system can be used for children as a modified T-piece circuit, it has been advocated as an all purpose truly universal anaesthetic breathing system. ${ }^{10.11}$

The purpose of this investigation was to evaluate the MERA $F$ anaesthetic system in adults under clinical conditions during spontaneous 
respiration. We elected to compare this system with the Bain co-axial circuit at FGF rates now recommended $\left(100 \mathrm{ml} \cdot \mathrm{kg}^{-1} \cdot \mathrm{min}^{-1}\right)$ in spontancously breathing adults.

\section{Materials and Methods}

\section{Description of MERA F}

The MERA $F$ is a co-axial anaesthetic breathing system, that is, a tube in a tube (Figures 1 \& 3 ). The inspiratory fresh gas is delivered to the patient through an inner tube and exhaled gas is carried away in an outer large diameter tube, in a manner identical to the Bain system. The MERA $F$ can be used as a modified Mapleson ' $D$ ' circuit as illustrated in Figure 2. By preserving the co-axial construction Fukunaga ${ }^{10}$ has ensured that the MERA F's light-weight construction is as convenient to use as the Bain system.

The purpose of the adaptor, supplied with each MERA $F$, is to direct expired gas from the outer limb of this coaxial circuit to the expiratory valve of the gas machine (Figure 3c). When the anaesthetist uses the MERA $F$ with this adaptor in place, the inner tube of the co-axial system is connected to the inspiratory valve of a standard "circle" machine, while the adaptor (connected to the outer tube of this system) leads to the expiratory valve. The patient can then inspire gas only from the inner tube (Figure 3a) of the MERA $F$, because the valves of the "circle" apparatus prevent the entrainment of gas from the expiratory limb (outer tubing). Similarily, on expiration, the inspiratory valve of the machine closes, preventing exhaled gas from passing down the inner tube of this system (Figure 3b).

In this study all patients were breathing spontaneously during anaesthesia through a MERA $F$ system used with the adaptor as described. These MERA $F$ studies were conducted using the standard circle machine including a carbon dioxide absorber. The measurements made with this system are compared to those made with the Bain modification of the Mapleson ' $D$ ' breathing system at the same FGF rate.

\section{Study Protocol}

Six healthy patients (ASA 1) were studied during general anaesthesia in the supine position for exploration and repair of peripheral nerve lesions. These patients (age range 15-40 years) had no clinical evidence of cardiopulmonary disease by history or physical examination. An institutional review committee agreed that no formal consent was required from participating patients.
Each unpremedicated patient was given sodium thiopentone $3-5 \mathrm{mg} \cdot \mathrm{kg}^{-1}$ to facilitate intubation. Halothane in oxygen was used to maintain anaesthesia. Nitrous oxide was not used, since it is known to interfere with the analysis of carbon dioxide in respiratory gases.

After intubation, the tracheal tube was attached to a calibrated, heated pneumotachograph (Fleisch \#2), which was connected to a differential transducer (Statham PM 5). The pneumotachograph was calibrated with oxygen and linear accuracy to a flow rate of 20 litres per minute was demonstrated. The flow signal from the transducer was used to measure duration of inspiration $\left(\mathrm{T}_{\mathrm{l}}\right)$, and respiratory frequency ( $\left.\mathrm{f}\right)$. This flow signal was also integrated by the pneumotachograph transducer to measure tidal volume (VT).

The concentration of carbon dioxide in the respiratory gases was recorded continuously using a rapidly responding Godart capnograph (sampling rate $11 \mathrm{ml} / \mathrm{s}$ ) which sampled gas from a catheter with its tip at the distal end of the tracheal tube. All variables were recorded continuously on a Mingograph 800 recorder at a paper speed of $25 \mathrm{~mm} / \mathrm{s}$. The volume of carbon dioxide inspired (inspired $\mathrm{CO}_{2}$ load) was calculated as previously described ${ }^{4}$ for two representative breaths at each measurement. This inspired volume of carbon dioxide was calculated by multiplying the instantaneous concentration of carbon dioxide inspired by the total inspiratory flow rate at that time. These measurements were made at $0.02 \mathrm{~s}$ intervals throughout a breath. These values form a curve that represents the inspired flow of carbon dioxide during the breath. The area under this curve was measured by planimetry to determine the volume of carbon dioxide inspired.

The accuracy of the oxygen flowmeter, and thus FGF rate, was verified by passing oxygen through the calibrated pneumotachograph. Measurements were not made until a stable anaesthetic state, satisfactory for the surgical procedure, was obtained (30-40 minutes after induction). All measurements were made with a FGF of $100 \mathrm{ml} \cdot \mathrm{kg}^{-1} \cdot \mathrm{min}^{-1}$. The first measurement was noted no less than 15 minutes after the initial surgical stimulus.

After the initial measurement, the circuit was changed to the alternate anaesthetic system for comparison. When a stable respiratory pattern and constant end-tidal carbon dioxide concentration was present with the new circuit, measurements were repeated. The Bain system was used as a modified Mapleson 'D' system (Figure 2) as 
described by Bain and Spoerel. The MERA F system was used as a modified (co-axial) circle system as described by Fukunaga ${ }^{10}$ (Figures $1 \&$ $3)$. When circuit changes were made, a 15-20 minute interval was allowed for stabilization before noting the measured parameters of ventilation and blood carbon dioxide tensions. The number of circuit changes in each study was determined by the duration of the surgical procedure. FGF rate and depth of anaesthesia were not altered during the study period.

At each measurement free flowing peripheral venous blood obtained from a forearm vessel was sampled and the $\mathrm{PCO}_{2}$ of this blood was measured. With similar methodology, ${ }^{12}$ the $\mathrm{PCO}_{2}$ in peripheral venous blood has been shown to be within $\pm 0.13 \mathrm{kPa}$ ( 1 torr) of arterial $\mathrm{PCO}_{2}$ values in anaesthetized subjects.

Data are presented as means \pm 1 S.D. Serial measurements in each patient were compared using the Student ' $t$ ' test to compare the MERA $F$ and the Bain circuit. If $p<0.05$, the changes were considered significant.

\section{Results}

In the six patients studied, we changed from the BAIN to the MERA $F$ circuit on nine occasions, and from the MERA F to the BAIN system seven times. Each time the BAIN circuit was used the inspiratory carbon dioxide plateau on the capnograph trace (Figure 4) was higher than on the preceding or following measurement made with the MERA F system (Table I).

In every patient the calculated volume of carbon dioxide inspired was higher when the BAIN circuit was used (Table I). The mean volume of carbon dioxide inspired by patients breathing through the BAIN system was significantly greater $(8.9 \pm 3.3 \mathrm{ml})$ than when the MERA F was used $(6.8 \pm 3.2 \mathrm{ml}, \mathrm{p}<0.001)$.

This difference between volumes of carbon dioxide inspired was not affected by the order of change. When the circuit was changed from the Bain to the MERA $F$ the mean volume of carbon dioxide inspired decreased from $8.9 \pm 2.8 \mathrm{ml}$ to $6.6 \pm 2.8 \mathrm{ml}(\mathrm{p}<0.005)$. When the circuit was changed from the MERA $F$ to Bain the mean volume of carbon dioxide inspired increased from $7.0 \pm 3.4 \mathrm{ml}$ to $8.8 \pm 3.4 \mathrm{ml}(\mathrm{p}<0.01)$.

The changes in ventilation that resulted from alternating circuits are shown in Table I. The increase in minute ventilation with the Bain circuit was due to an increase in tidal volume as respiratory frequency remained constant. The
PATIENT: R.O. (Figure 4a)

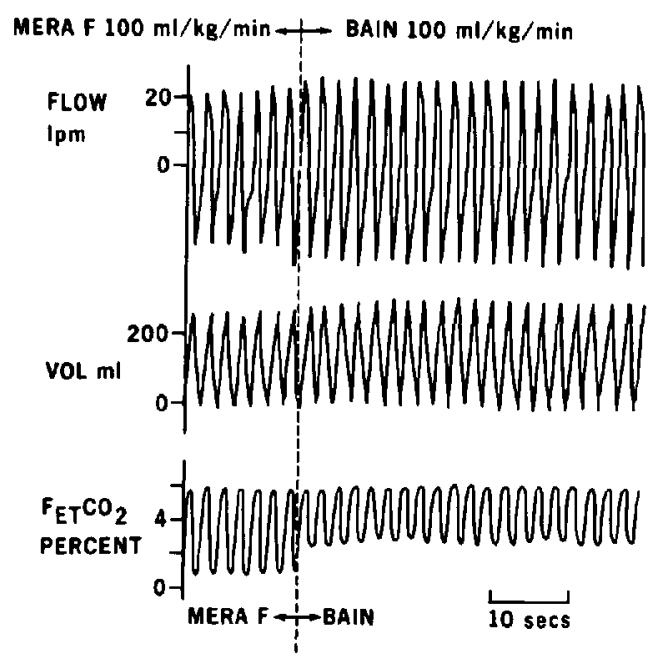

PATIENT: G.S. (Figure $4 b$ )

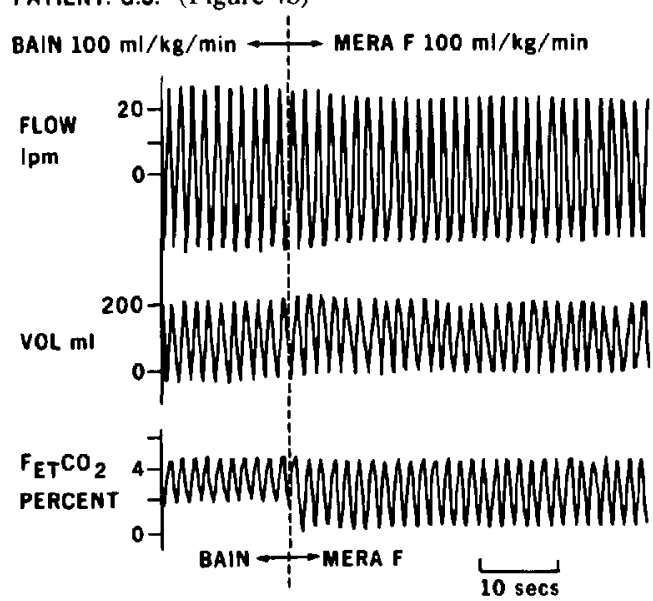

Figure 4 Illustrative traces from two of the patients reported in this study are shown. The changes in tidal volume, inspiratory flow rate and inspired concentration of carbon dioxide are shown. When the MERA $F$ was replaced with a BAIN circuit, an instantaneous increase in the inspired concentration of carbon dioxide was noted (Figure 4a). The maximal ventilatory response to this rise in the concentration of carbon dioxide inspired occurred over a period of time. Similarly, when the BAIN system was replaced with the MERA $F$, an instantaneous decrease in inspired concentration of carbon dioxide was noted (Figure 4b).

mean inspiratory flow rate $\left(\mathrm{VT}_{\mathrm{T}} / \mathrm{T}_{\mathrm{I}}\right)$ calculated at each measurement was increased when the Bain circuit was used as compared to when the MERA $\mathrm{F}$ was studied in the same patient.

The $\mathrm{PCO}_{2}$ ranged from 4.3 to $8.0 \mathrm{kPa}(32$ 60 torr) when the Bain circuit was used as compared to a range of 4 to $7.6 \mathrm{kPa}$ (30-57 torr) with the MERA $F$ circuit. There is no significant 
TABLE I

\begin{tabular}{lccc}
\hline & Bain & MERA F & Significance, $\mathrm{n}=16$ \\
\hline $\mathrm{VT}(\mathrm{ml})$ & $224.2 \pm 57.8$ & $193.3 \pm 28.9$ & $\mathrm{p}<0.025$ \\
$\mathrm{f}$ (per min.) & $36.0 \pm 6.7$ & $35 \pm 8$ & $\mathrm{~N} / \mathrm{S}$ \\
$\mathrm{VE}(1 / \mathrm{min})$ & $7.99 \pm 2.14$ & $6.68 \pm 1.78$ & $\mathrm{p}<0.01$ \\
$\%$ Insp. $\mathrm{CO}_{2}$ & & & \\
$\quad$ (plateau) & $1.99 \pm 0.56$ & $0.64 \pm 0.3$ & $\mathrm{p}<0.001$ \\
$\mathrm{PCO}_{2}$ (kPa) & $6.06 \pm 1.07$ & $5.98 \pm 1.27$ & $\mathrm{~N} / \mathrm{S}$ \\
$\quad$ (torr) & $45.5 \pm 8.05$ & $44.9 \pm 9.51$ & \\
$\mathrm{VT} / \mathrm{TI}$ & $305.11 \pm 87.4$ & $256.14 \pm 80.1$ & $\mathrm{p}<0.01$ \\
$\mathrm{CO}_{2} \operatorname{load}(\mathrm{ml})$ & $8.85 \pm 3.34$ & $6.75 \pm 3.24$ & $\mathrm{p}<0.001$ \\
\hline
\end{tabular}

Mean \pm 1 standard deviation.

difference in mean $\mathrm{PCO}_{2}$ values (Table I) between the grouped MERA $F$ studies and the Bain studies. The largest difference in $\mathrm{PCO}_{2}$ noted in one of our six patients was $1.6 \mathrm{kPa}$ (12.0 torr). This subject reduced $\mathrm{PCO}_{2}$ from $8.0 \mathrm{kPa}$ (60 torr) to $6.4 \mathrm{kPa}$ (48 torr) when the Bain system was replaced with the MERA $F$, in spite of a reduction in $\dot{V}_{E}$ which occurred simultaneously $(7.81 / \mathrm{m}$ to $6.3 \mathrm{l} / \mathrm{m}$ ) and a reduction in carbon dioxide load of 60 per cent.

\section{Discussion}

\section{Comparison of Circuit Design}

In clinical use the MERA F circuit is convenient, flexible, and light weight; advantages contributing to the popularity of the Bain circuit. The disadvantage of the MERA $F$ is its length. The Bain circuit has a standard length of $163 \mathrm{~cm}$, making it convenient for anaesthetic use where surgical access to the head and neck is necessary. The MERA $F$ is considerably shorter $(90 \mathrm{~cm})$. However, during controlled ventilation both systems function independent of conducting tube and reservoir length. There is no technical reason to limit the length of the MERA F. During spontaneous ventilation the MERA $F$ is used with inspiratory valves, which prevent the rebreathing of carbon dioxide. Thus the length of the co-axial tubing is unimportant.

The MERA F circuits used in this study were obtained from our Japanese colleague. This circuit has been widely used in Japan since 1979 as an all-purpose anaesthetic breathing system. The diameter of the tubes composing the co-axial MERA F system are slightly different from those in the Bain circuit. The outer plastic tube of the MERA $F$ has a diameter similar to the Bain $(22 \mathrm{~mm})$. The diameter of the inner tube is $10 \mathrm{~mm}$ in the MERA F, which is larger than that of the Bain system $(6.3 \mathrm{~mm})$. This reduces the crosssectional area of the expiratory limb in the
MERA F. Even at the peak FGF rates measured in this study the increase in resistance due to this reduced expiratory area is not clinically significant. We used the technique described by Nunn ${ }^{16}$ of measuring the pressure difference at a given flow rate as a measure of resistance. At a flow rate of 20 litres per minute we have found that the pressure drop across the MERA $F$ circuit is $0.025 \mathrm{kPa}\left(0.25 \mathrm{~cm} \mathrm{H}_{2} \mathrm{O}\right)$, whereas that across the Bain circuit is $0.014 \mathrm{kPa}\left(0.04 \mathrm{~cm} \mathrm{H}_{2} \mathrm{O}\right)$. To put these values in perspective, the pressure difference across a Heidbrink relief valve, ${ }^{16}$ at a flow rate of 20 litres per minute, is $0.2 \mathrm{kPa}(2.0 \mathrm{~cm}$ $\mathrm{H}_{2} \mathrm{O}$ ). This small increase in expiratory resistance imposed by the MERA F circuit is not significant in comparison to the valves and carbon dioxide absorber which are present in the usual "circle" system. Whether this increased resistance $(0.025 \mathrm{kPa})$ with the MERA $F$ as compared to the Bain $(0.014 \mathrm{kPa})$ is significant in children remains conjectural.

\section{Rebreathing of Carbon Dioxide}

The major factor preventing widespread use of the Bain as a "universal circuit" 13 is the rebreathing of carbon dioxide at low FGF which occurs during spontaneous respiration in adults. ${ }^{4}$ The degree of rebreathing and the patient's response to this inspired carbon dioxide challenge is both unpredictable and uncontrollable. ${ }^{4}$ Therefore, in comparing the Bain system with the MERA $F$, it is important to assess the volume of carbon dioxide inspired and the patient's response to this inspired carbon dioxide load.

The patients studied were all healthy (ASA I) with no premedication to alter responsiveness to carbon dioxide. The depth of anaesthesia was held constant between measurements. In our previous study, ${ }^{4}$ using a similar technique, endtidal halothane concentrations were measured and found to be 1.1 per cent (1.5 MAC). The minute volume and carbon dioxide volume in- 
spired are not significantly different in this study; hence we believe the level of anaesthesia was comparable to our previous cases.

When the circuits were alternated, the changes in volume, minute ventilation, inspired carbon dioxide plateau, and inspired volume of carbon dioxide (Table I) were all significantly higher with the Bain system. This pattern is identical to the increased rebreathing demonstrated in our previous study ${ }^{4}$ in which the Bain was compared to the circle absorber system. The inspired volume of carbon dioxide increased significantly ( 31 per cent) when the Bain system was replaced by the MERA $F$ at the same FGF.

The fact that rebreathing was occurring could be detected easily by continuous monitoring of inspired gas in the tracheal tube (Figure 4). Ungerer ${ }^{14}$ has shown that the inspired carbon dioxide concentration can be reduced significantly by increasing FGF to $150 \mathrm{ml} \cdot \mathrm{kg}^{-1}$. $\min ^{-1}$. Our previous study ${ }^{4}$ demonstrated that the FGF required to eliminate rebreathing with the Bain system varied widely from patient to patient.

The volume of carbon dioxide rebreathed is influenced by the respiratory waveform. This is a factor over which the anaesthetist has little control during spontaneous respiration. The respiratory waveform with halothane encourages the rebreathing of carbon dioxide ${ }^{15}$ as a result of the very brief end-expiratory pause at these rapid respiratory rates (Table I). The waveform with enflurane, however, is characterized by a lower mean inspiratory flow rate $(\mathrm{VT} / \mathrm{TI})$ and a longer end-expiratory pause. Because of this difference in respiratory waveform, much less rebreathing occurs when enflurane is used with the Bain circuit at low FGF rates ${ }^{15}$. Halothane was chosen over enflurane for this study because it preserves the responsiveness to carbon dioxide of patients under anaesthesia, even though this waveform favours rebreathing with the Bain system. This study, then, compares the Bain and the MERA F systems under conditions encountered in clinical anaesthetic practice with healthy, unpremedicated patients.

The "mean inspiratory gas composition" is difficult to measure in the presence of rebreathing. It cannot be derived from a direct plot of the instantaneous gas composition against time, since the required value is the concentration integrated with respect to volume and not to time. ${ }^{16}$ Thus the increase in inspiratory carbon dioxide plateau from 0.64 per cent with the MERA F to 1.99 per cent when the BAIN system was used, only reflected the true increase in rebreathing, measured by integrating the inspired flow of carbon dioxide per breath. ${ }^{4}$. This 31 per cent increase in volume of carbon dioxide inspired when the Bain system was used (Table I) reflects a true increase in rebreathing. In our previous report ${ }^{4}$ the inspired volume of carbon dioxide with the circle system was equivalent to that inspired with the BAIN circuit at a FGF of $250 \mathrm{ml} \cdot \mathrm{kg}^{-1} \cdot \mathrm{min}^{-1}$.

\section{Ventilatory Response to Carbon Dioxide Re- breathing}

When low FGF rates are used with the BAIN circuit and rebreathing occurs, patients under halothane anaesthesia increase minute ventilation primarily by increasing the inspiratory flow rate $(\mathrm{VT} / \mathrm{TI})$. Therefore, the increased concentration of carbon dioxide in inspired gas was really an increase in the fraction of carbon dioxide in a higher volume inspired (VT) (Table I). The VT increased as a direct result of the increased $\mathrm{VT} / \mathrm{TI}_{\mathrm{I}}$. That rebreathing occurred with the BAIN circuit at a FGF of $100 \mathrm{ml} \cdot \mathrm{kg}^{-1} \cdot \mathrm{min}^{-1}$ was indisputable when one examined the capnograph traces (Figure 4) during a circuit change. The rise in the inspiratory carbon dioxide plateau was instantaneous with no change in anaesthetic depth or surgical stimulation, in every patient.

The ventilatory response to the carbon dioxide challenge imposed by the BAIN circuit at FGF rates of $100 \mathrm{ml} \cdot \mathrm{kg}^{-1} \cdot \mathrm{min}^{-1}$ occurred over several minutes. The measured increases in tidal volume and minute ventilation ( $\dot{V} E)$, which result from using the BAIN system, were variable between patients.

Our previous study ${ }^{4}$ showed that as FGF was increased using the BAIN system, minute ventilation decreased in response to the reduced inspired carbon dioxide load. In some patients the end tidal carbon dioxide (and blood $\mathrm{PCO}_{2}$ ) was found to decrease significantly, in spite of the decreased $\dot{V}_{E}$. The change in $\mathrm{PCO}_{2}$ which resulted from the reduced inspired carbon dioxide load was dependent on the change in $\dot{V}_{E}$ that occurred simultaneously. In this study, the largest reduction in $\mathrm{PCO}_{2}$, resulting from replacing the BAIN circuit with a MERA $F$, was $1.6 \mathrm{kPa}$ (12 torr) at the same FGF. This elevation in $\mathrm{PCO}_{2}$ was preventable by reducing the inspired carbon dioxide load. This may be accomplished by increasing FGF with the BAIN system (as in our previous report), ${ }^{4}$ or by changing to a nonrebreathing anaesthetic system (eg. MERA F) as in this study. It should also be noted that even 
those patients who can respond to an inspired carbon dioxide load to maintain a constant $\mathrm{PCO}_{2}$, do so at a cost of increased $\dot{V}_{E}$ (Table I). This increment in $\dot{V E}$ may not reduce $\mathrm{PCO}_{2}$, and represents a reduction in the patient's ventilatory reserve. ${ }^{4}$

When comparing the average $\mathrm{PCO}_{2}$ values in each group there is no significant difference (Table 1). This results from the finding that some patients can maintain $\mathrm{PCO}_{2}$ constant when the BAIN circuit is used, by increasing VंE substantially. ${ }^{4}$ This is consistent with the data reported by Spoerel, et al $^{6}$ and emphasizes the insensitivity of mean arterial carbon dioxide values as a measure of the presence or absence of rebreathing. Reporting the mean $\mathrm{PCO}_{2}$ value in a population of patients obscures the effect of rebreathing on individual members of that group who cannot compensate adequately for the inspired carbon dioxide load, and hence become hypercapnoeic. The mean $\mathrm{PCO}_{2}$ value of the group may not change significantly in spite of this hypercapnia in some of its members.

\section{SUMMARY}

In conclusion, the MERA F circuit can be used for controlled ventilation in a manner identical with the BAIN system. This permits the anaesthetist to predictably control $\mathrm{PCO}_{2}$ by controlled rebreathing, ${ }^{2}$ with the associated advantage of increased inspired humidity ${ }^{17}$ and the avoidance of unnecessary respiratory alkalaemia. ${ }^{18.19}$ The construction of the co-axial MERA $F$ preserves the convenient features introduced by BAIN, with the exception of tubing length. However, from a functional point of view the co-axial tubing can be lengthened without any alteration in the rebreathing characteristics for either spontaneous or controlled ventilation.

The major advantage of the MERA F system would appear to be the avoidance of rebreathing during spontaneous respiration at low FGF. This study demonstrates that the carbon dioxide rebreathed with the MERA F system at a FGF of $100 \mathrm{ml} \cdot \mathrm{kg}^{-1} \cdot \min ^{-1}$ is significantly less than that with the BAIN circuit at the same FGF. In fact, we have used the MERA $F$ at even lower FGF $\left(50 \mathrm{ml} \cdot \mathrm{kg}^{-1} \cdot \mathrm{min}^{-1}\right)$ without demonstrable rebreathing. This difference is due to the adaptation of the co-axial circuit to the inspiratory and expiratory valves of the standard anaesthetic circle system (Figures $1 \& 3$ ) which prevent rebreathing from the expiratory tubing. Although not all patients become hypercapnoeic with re- breathing in the BAIN system, those who cannot compensate adequately for the inspired carbon dioxide load, develop increased $\mathrm{PCO}_{2}$ levels. ${ }^{4}$ This hypercapnia can be prevented by either increasing $\mathrm{FGF}^{4}$ or by choosing another anaesthetic circuit. The MERA F system has been widely used for this reason; clinical reports by Fukunaga ${ }^{10}$ as well as Tanaka and Umedi" indicate a similar degree of satisfaction with this system.

The MERA $F$ preserves many of the advantages of the BAIN system, and effectively prevents the rebreathing found in adults during spontaneous respiration at low FGF.

\section{ACKNOWLEDGEMENTS}

The authors wish to acknowledge the technical help of Gary Caskennette and the financial assistance of Ohio Medical Products Canada. The co-operation of Professor Alan Hudson and the neurosurgical operating-room nurses was invaluable. We appreciate the work of Patricia Slusarenko who typed the manuscript.

\section{REFERENCES}

1. Conway, W.E., Conway, C.M. \& Seeley, N.F. Spontaneous ventilation with the Bain anaesthetic system. Brit. J. Anaesth. 49: 1245 (1977).

2. Rose, D.K., Byrick, R.J.\& Froese, A.B. Carbon dioxide elilmination during spontaneous ventilation with a modified Mapleson D system: studies in a lung model. Canad. Anaesth. Soc. J. 25: 353 (1978).

3. Bain, J.A. \& Spoerel, W.E. Bain circuit - Letter to the Editor. Canad. Anaesth. Soc. J. 26: 65 (1979).

4. BYRICK, R.J. Respiratory compensation during spontaneous ventilation with the Bain circuit. Canad. Anaesth. Soc. J. 27: 96 (1980).

5. Mapleson, W.W. The elimination of rebreathing in various anaesthetic systems. Brit. J. Anaesth. 26: 323 (1954).

6. Spoerel, W.E., Aitken, R.R. \& Bain, J.A. Spontaneous respiration with the Bain breathing circuit. Canad. Anaesth. Soc. J. 25: 30 (1978).

7. Goodwin, K. The Bain circuit - Letter to the Editor. Canad. Anaesth. Soc. J. 23: 675 (1976).

8. MANSELL, W.H. Spontaneous ventilation with the Bain circuit at low fresh gas flow rates: a case report. Canad. Anaesth. Soc. J. 23: 432 (1976).

9. Shiozawa, S. \& Sato Mitsuo. Evaluation of Bain Circuit. J. Clinical Anesthesia (Tokyo) 2: 247-253 (1978) (in Japanese).

10. Fukunaga, A.F. A compact multipurpose breathing circuit: An application to the anesthetic circle system. Jap. J. Anesth. 27(10): 113 (1978) (in Japanese)

11. TANAKA, T. \& UMEDI, Y. Clinical validity of MERA F Breathing system for anesthesia. Hiroshima J. Anesth. 15: 163 (1979). 
12. France, C.J., Eger, E.I. \& Bendixen, H.H. The use of peripheral venous blood for $\mathrm{Ph}$ and carbon dioxide tension determinations during general anesthesia. Anesthesiology 40: 311 (1974).

13. Henville, J.D. \& Adams, A.P. The Bain anaesthetic system. Anaesthesia 31: 247 (1976).

14. UNGERER, M.J.A. A comparison between the Bain and Magill systems during spontaneous breathing. Canad. Anaesth. Soc. J. 25: 122 (1978).

15. BYRICK, R.J.\& JANSSEN, E.G. Respiratory waveform and rebreathing in T-piece circuits: A comparison of enflurane and halothane waveforms. Anesthesiology 53: 371 (1980).
16. Nunn, J.F. Applied physiology. Second Edition, London, Butterworths (1977) pg 233, 106.

17. Ramanathon, S., Chalon, J., Capan, L., Patel, C. \& TuRndorfF, H. Rebreathing characteristics of the Bain anesthesia circuit. Anesth. Analg. 56: 822 (1978).

18. Rose, D.K. \& Froese, A.B. The regulation of $\mathrm{Pa}_{\mathrm{CO}_{2}}$ during controlled ventilation of children wtih a T-piece. Canad. Anaesth. Soc. J. 26: 104 (1979).

19. Bain, J.A. \& Spoerel, W.E. Flow requirements for a modified Mapleson System during controlled ventilation. Canad. Anaesth. Soc. J. 20:629 (1973).

\section{RÉSUMÉ}

Cette étude compare les caractéristiques sur le rebreathing de la modification par Bain du circuit Mapelson D avec le MERA F utilisé avec le système circulaire sur l'appareil d'anesthésie. Six adultes en bonne santé anesthésiés à l'halothane ont été étudiés en respiration spontanée. L'importance du rebreathing a été évalué par la mesure du volume de gaz carbonique à chaque respiration. Le volume courant, la fréquence respiratoire et la $\mathrm{Pa}_{\mathrm{CO}_{2}}$ ont aussi èté notés. Les études ont été effectuées d'abord avec le Bain ou le système MERA F et on est ensuite passé à l'autre circuit pour étude subséquente. Toutes ces mesures ont été faite avec un débit de gaz frais de $100 \mathrm{ml} \cdot \mathrm{kg}^{-1} \cdot \mathrm{min}^{-1}$ tel que recommandé pour le système Bain.

Le volume de gaz carbonique inspiré (rebreathing) avec le Bain a été plus élevé de façon significative qu'avec le MERA F. Bien que la $\mathrm{PCO}_{2}$ moyenne n'ait pas été plus basse de façon significative lorsqu'on employait le MERA $F$, certains patients qui ne pouvaient pas compenser adéquatement pour le volume de gaz carbonique inspiré sont devenus hypercapniques (maximum $8 \mathrm{kPa}$ ou 60 torr). Cette hypercapnie n'est pas survenue lors de l'emploi du système MERA $F$.

Le MERA F est un circuit co-axial qui combine les avantages du conduit d'alimentation cheminant à l'intérieur et d'un rebreathing accessible pendant la ventilation contrôlée. Par ces caractéristiques il ne diffère pas du circuit Bain. Le système MERA F a cependent cet avantage de pouvoir s'adapter aux systèmes circulaires communément employé sur nos appareils d'anesthésie en respiration spontanée chez les adultes. Ceci élimine la réinspiration du gaz carbonique qui survient chez les adultes en respiration spontanée même lorsque le débit d'alimentation de gaz frais est de $100 \mathrm{ml} \cdot \mathrm{kg}^{-1}$. Le seul désavantage du système MERA F utilisé chez l'adulte est sa longueur $(90 \mathrm{~cm})$; toutefois on peut l'allonger sans en altérer les caractéristiques fonctionnelles. 